\title{
MeCANismos CONTRA LAS Sentencias de la Corte Constitucional COLOMBIANA
}

\author{
Semillero de Derecho Procesal Hernando Devis Echandía \\ de la Universidad Libre, Seccional Cúcuta*
}

\section{Resumen:}

La reciente historia jurídica de Colombia se divide en dos: antes y después de la Constitución Política de 1991, con la cual se creó una institución que ha mejorado nuestro derecho: la Corte Constitucional, que ha protegido derechos que antes era imposible ejercer como los de los menores, mujeres embarazadas, personas de la tercera edad, etc. La historia se encargará de premiar la labor de la Corte. A pesar de todo lo bueno, la idea de la ponencia surgió de esta pregunta: ¿la Corte Constitucional puede violar derechos fundamentales? En principio, por ser la Corte la llamada a garantizar la integridad y supremacía de la Constitución y especialmente por el papel cumplido desde 1992 como protectora de los derechos fundamentales y de ser la institución mejor vista por la sociedad, parece que no. Sin embargo, hay

* Este artículo fue presentado por el Semillero de Derecho Procesal Hernando Devis Echandía de la Universidad Libre, Seccional Cúcuta, como ponencia en el XIII Concurso Internacional para Estudiantes de Derecho, Nivel Pregrado, en el marco del XXXIII Congreso Colombiano de Derecho Procesal, celebrado en Cartagena de Indias en septiembre de 2012, obteniendo el segundo lugar.

El Semillero de Derecho Procesal estuvo formado por Adriana Angélica Castañeda Zabala, Angie Daniela Contreras Burgos, Adriana María Ayala Páez, Angie Tatiana Peinado Ibarra, Camilo José Puello Rincón, Daniela Fernanda Vega Vanegas, Christian Eduardo Laguado Serrano, Liliana Maritza Quintero Marciales, Jefferson Arley Castellanos Castellanos y Ronald Jesús Sanabria Villamizar, quien fue el ponente.

Fueron directores de la ponencia, los doctores Carlos Alberto Colmenares Uribe y Samir Alberto Bonett Ortiz (directores del Semillero de Derecho Procesal) y Cindy Charlotte Reyes Sinisterra (Coordinadora del Semillero de Derecho Procesal). 
ejemplos que prueban lo contrario y en este caso la pregunta es: ¿qué puede hacer una persona a quien la Corte Constitucional le viola un derecho fundamental? Vamos a intentar responder esta pregunta, partiendo de que la Corte hace parte de la Rama Judicial y en la estructura del Estado es un órgano susceptible de violar derechos fundamentales, como cualquier juez de la República. Los mecanismos de protección son la solicitud de nulidad, petición de tutela y Sistema Interamericano de Derechos Humanos.

Palabras clave: Corte Constitucional, mecanismos de protección, solicitud de nulidad, petición de tutela y Sistema Interamericano de Derechos Humanos.

\begin{abstract}
The recent juridical history of Colombia divides in two: before and after the Political Constitution of 1991, with which there was created an institution that has improved our right: the Constitutional Court, which has protected rights that before it was impossible to practice as those of the minors, pregnant women, persons of the third age, and other examples. The history will reward Court's labor. Adittionally of good every things, the idea of the presentation arose from this question: ¿Can Constitutional Court violate fundamental rights? At first, for being the Court calls to guaranteeing the integrity and supremacy of the Constitution and especially for the paper fulfilled from 1992 of protective of the fundamental rights and of being the best institution for the society, it seems not. However, there are examples that prove opposite and in this case the question is: When the Constitutional Court violates a right to a person, ¿What can this person do? Let's try to answer this question, assuming that the Court does part of the Judicial Branch and in the structure of the state, it's an organ that can violate fundamental rights, as any judge of the Republic. The protection mechanisms are the request of nullity, petition for guardianship and the Inter-American Human Rights System.
\end{abstract}

Key words: Constitutional Court, protection mechanisms, request of nullity, petition for guardianship and the Inter-American Human Rights System. 


\section{INTRODUCCIÓN}

"el poder -todos los poderes, sean estos públicos o privadostienden, en efecto e ineludiblemente, a acumularse en forma absoluta y a liberarse del derecho".

Luigi Ferrajoli ${ }^{1}$.

Cuando se habla de Constitución se habla de valores, principios y reglas que rigen las actuaciones de un Estado. El famoso caso estadounidense Marbury vs. Madison, los invaluables aportes del profesor Hans Kelsen², lo dicho por el profesor Robert Alexy $^{3}$, son sólo tres ejemplos de la riqueza de la temática constitucional.

El Estado colombiano, con la creación de la Corte Constitucional en 1991, decidió otorgarle a un tribunal la función de proteger la integridad y supremacía de la Constitución. Esta nueva Corte es indiscutiblemente un acierto en el Estado colombiano. Ello se puede inferir de los innumerables casos en los cuales sus pronunciamientos han servido para que se respeten los derechos, especialmente los fundamentales. Se debe resaltar su ardua labor tendiente a la protección, respeto y garantía de los derechos fundamentales de todos los habitantes de nuestro país. La historia se encargará de darle los méritos a este tribunal.

No obstante, el Semillero de Derecho Procesal Hernando Devis Echandía formuló el siguiente cuestionamiento: ¿la Corte Constitucional puede violar derechos fundamentales?, en virtud de un estudio de casos hemos llegado a la conclusión de que sí. De forma inmediata, surgió una nueva pregunta: ¿qué mecanismos proceden en contra de las providencias de la Corte Constitucional colombiana? Esta investigación va dirigida a encontrarle una respuesta a tan complejo interrogante.

\section{La Corte Constitucional en la estructura Judicial}

A partir de la Constitución Política de 1991, la jurisdicción en Colombia se divide principalmente en tres: 1) jurisdicción ordinaria (CP, arts. 234-235), 2) jurisdicción administrativa (Ibídem., arts. 236-238) y 3) jurisdicción constitucional (Ibídem., arts. 239-245). La Corte Constitucional hace parte y es el máximo órgano de la jurisdicción constitucional. Luego, desde el punto de vista de la estructura judicial

FERRAJOLI, Luigi. El Garantismo y la Filosofía del Derecho. Bogotá: Universidad Externado de Colombia, 2000. p. 121.

2 KELSEN, Hans. Teoría General del Derecho y del Estado. México. 1950; Teoría Pura del Derecho. México: Universidad Nacional Autónoma de México. 1982; ¿Quién Debe ser el Defensor de la Constitución? Madrid: Tecnos S.A. 1995.

3 ALEXY, Robert. El concepto y la validez del derecho. Barcelona: Gedisa. 1994; Teoría de la Argumentación Jurídica. Madrid: Centro de Estudios Constitucionales. 1989. 
del Estado, es un juez, muy importante, a quien "se le confía la guarda de la integridad y supremacía de la Constitución” (Ibídem., art. 241), pero en todo caso, un juez y como cualquier juez, es posible que viole derechos fundamentales, pues el juez, como humano, no es ajeno al error.

\section{1 ¿la Corte Constitucional puede violar derechos fundamentales?}

La reciente historia jurídica de Colombia se divide en dos: antes y después de la Constitución Política de 1991, con la cual se creó una institución que ha mejorado nuestro derecho: la Corte Constitucional, que ha protegido derechos que antes era imposible ejercer, como los de los menores, mujeres embarazadas, personas de la tercera edad, etc. La historia se encargará de premiar la labor de la Corte. A pesar de todo lo bueno, ¿la Corte Constitucional puede violar derechos fundamentales? En principio, por ser la Corte la llamada a garantizar la integridad y supremacía de la Constitución y especialmente por el papel cumplido desde 1992 como garante de la protección de los derechos fundamentales y de ser la institución mejor vista por la sociedad, parece que no. Sin embargo, hay ejemplos que prueban lo contrario y, en este caso, la pregunta sería: ¿qué puede hacer una persona a quien la Corte Constitucional le viola un derecho fundamental? Vamos a intentar responder esta pregunta, partiendo de que la Corte hace parte de la Rama Judicial y en la estructura del Estado es un órgano susceptible de violar derechos fundamentales, como cualquier juez de la República.

\subsection{Mecanismos contra las sentencias de la Corte Constitucional colombiana}

El estudio de esta ponencia trata tres mecanismos, excepcionales, residuales y subsidiarios, para protegerse de una eventual violación de un derecho fundamental: 1) solicitud de nulidad de la sentencia, 2) petición de tutela y 3) Sistema Interamericano de Derechos Humanos.

\section{SOlicitud DE NULIDAD}

\subsection{Definición}

La nulidad es una sanción que resta eficacia a un acto jurídico. Alessandri Bessa define la nulidad como "la sanción legal establecida para la omisión de los requisitos y formalidades que las leyes prescriben para el valor de un acto, según su especie y la calidad o estado de las partes que en él intervienen, y que consiste en el desconocimiento de sus efectos jurídicos, estimándose como si nunca hubiese sido ejecutado" . Por su parte, la noción de nulidad para Jorge Joaquín Llambías "implica

\footnotetext{
4 ALESSANDRI BESSA, Arturo. La nulidad y la recisión en el Derecho Civil. T. I. Santiago de Chile: Imprenta Universitaria. 1962, p. 4.
} 
un conjunto sistemático de disposiciones legales que privan de sus efectos propios a los actos violatorios de una norma de derecho imperativo, es decir, una sanción legal que priva de efectos a un acto jurídico en razón de una causa originaria” ${ }^{5}$.

La nulidad, ya sea absoluta o relativa, requiere de una declaración judicial; lo que quiere decir que el acto viciado ostenta una presunción de validez que hace que hasta tanto un juez, unipersonal o colegiado, por medio de una providencia declare su nulidad, el acto jurídico genera pleno efectos jurídicos y es de obligatorio cumplimiento. El efecto una vez declarada la nulidad es la eliminación del acto, lo que hace que se actué como si jamás hubiera existido.

El ordenamiento jurídico colombiano plantea la posibilidad de que se declare nula una sentencia de la Corte Constitucional.

\title{
2.2 Nulidad y cosa juzgada constitucional
}

La cosa juzgada constitucional es una garantía de la seguridad jurídica de un Estado, su existencia se justifica debido a que las providencias proferidas por la Corte Constitucional -el órgano encargado de interpretar la Constitución- deben ser cumplidas por todas sus miembros, sin excepción alguna. Sin embargo, si la Corte dicta una providencia, ya sea de tutela o de constitucionalidad, configurando la cosa juzgada constitucional, pero lo hace violando derechos fundamentales como el debido proceso, ¿prevalece la cosa juzgada constitucional o la efectiva protección de los derechos fundamentales?

Desde el nacimiento de la Corte Constitucional, se trató de dar una respuesta. El Decreto 2067 de 1991 que contiene el régimen procedimental de los juicios y actuaciones que deben surtirse ante la Corte Constitucional, establece en el art. 49:

\begin{abstract}
"Artículo 49. Contra las sentencias de la Corte Constitucional no procede recurso alguno.

La nulidad de los procesos ante la Corte Constitucional sólo podrá ser alegada antes de proferida el fallo. Sólo las irregularidades que impliquen violación del debido proceso podrán servir de base para que el Pleno de la Corte anule el proceso".
\end{abstract}

El primer inciso, otorga un valor de cosa juzgada absoluta a lo decidido por la Corte colombiana cuando establece: "contra las sentencias de la Corte Constitucional no procede recurso alguno". Sin embargo, habría una contradicción en el segundo inciso cuando establece un mecanismo contra las sentencias de la Corte Constitucional, esto es, la nulidad.

$\mathrm{Si}$ se analiza literalmente la norma citada se puede concluir la inclinación de ella hacía la prelación de la cosa juzgada constitucional. Sin embargo, como se verá

LLAMBÍAS, Jorge Joaquín. Efectos de la Nulidad y de la Anulación de los Actos Jurídicos. Buenos Aires: Edic. Arayú, 1953, p. 3. 
luego con más claridad, a la postre la Corte termina haciendo una ponderación, encontrando un punto intermedio entre las dos.

El Tribunal Constitucional colombiano ha considerado sano ampliar el espectro de aplicación del incidente de nulidad en contra de sus sentencias, ya sean sentencias de constitucionalidad, las sentencias de revisión de tutela y las sentencias de unificación de criterio. "La regla de la inmutabilidad de la cosa juzgada, sustentada en razones de seguridad jurídica, cuando entra en conflicto con la justicia intrínseca de decisión, plantea inevitablemente el tema de la "relativización" o flexibilización de sus efectos" 6 .

En el auto 73 de $2011^{7}$ la Corte Constitucional consideró:

"En conclusión, la solicitud de nulidad de las sentencias que profiera la Corte Constitucional es un trámite de configuración jurisprudencial relacionado con la protección del derecho al debido proceso, que tiene naturaleza excepcional y que está sometido a estrictos requisitos de procedencia..." (Subrayado fuera de texto).

Como se observa, la misma Corte partiendo de la base de lo falible de los seres humanos, y por lo tanto, de la misma Corporación, amplió el alcance del art. 49 del Decreto 2067 de 1991 vía jurisprudencia, propendiendo por una administración de justicia garantista, imponiendo el respeto real y efectivo de los derechos sobre las formas.

\subsection{Requisitos}

Es necesario hacer un estudio jurisprudencial para establecer de manera clara y entendible cuáles son los estrictos requisitos de procedencia, llamados de esta manera por la Corte Constitucional.

En el auto 5 de $1993^{8}$ por primera vez se decidió una solicitud de nulidad. En aquella ocasión la Corte negó la solicitud considerando que "la solicitud de nulidad de los procesos ante la Corte Constitucional sólo procede antes de proferido el fallo, tal como lo señala el artículo 49 del decreto 2067 de 1991. En el presente caso, la petición fue presentada el 12 de marzo de 1993, cuando la sentencia había sido pronunciada el 5 de febrero de 1993. Por lo anterior, es clara la improcedencia de la solicitud de nulidad, por ser abiertamente extemporánea".

En esta ocasión, la Corte interpretó el art. 46 de manera literal, proscribiendo cualquier posibilidad de presentar la solicitud una vez sea proferida la providencia.

6 BERIZONCE, Roberto Omar. "La 'Relatividad' de la Cosa Juzgada y sus Nuevos Confines". En: Revista del Instituto Colombiano de Derecho Procesal. Número 38. Bogotá: Ediciones del profesional, LTDA., 2012. p, 75.

7 Auto del 27 de abril de 2011, M.P. Mauricio González Cuervo.

8 Auto del 20 de mayo de 1993, M.P. Eduardo Cifuentes Muñoz. 
En la segunda solicitud de nulidad conocida por la Corte, en el Auto 8 de 19939, la Corporación cambió el concepto. Lo interesante del caso es que fue tan sólo meses después de haber proferido el auto citado en precedencia:

"Como la violación del procedimiento, es decir, del debido proceso, sólo se presentó en la sentencia, al dictar ésta, la nulidad comprende solamente la misma sentencia. Y, por lo mismo, únicamente podía ser alegada con posterioridad a ésta, como ocurrió. Nadie podría sostener lógicamente que la nulidad de la sentencia por hechos ocurridos en ésta, pudiera alegarse antes de dictarla.

Lo anterior no significa, en manera alguna, que exista un recurso contra las sentencias que dictan las Salas de Revisión. No, lo que sucede es que, de conformidad con el artículo 49 mencionado, la Sala Plena tiene el deber de declarar las nulidades que se presenten en cualquier etapa del proceso. Y la sentencia es una de ellas" (negrita del texto).

Estas dos primeros autos, que interpretan de manera claramente opuesta el art. 49 del Decreto 2067 de 1991, son el telón del estudio de un tema polémico para la tradición jurídica colombiana.

Un año después, en la tercera solicitud de nulidad conocida por la Corte, en el Auto 24 de $1994^{10}$ :

“...solamente podrá prosperar la nulidad cuando se vulnere un principio procesal establecido en la Constitución.

No podrán, entonces, invocarse como causal de nulidad las irregularidades en trámites legales, salvo que éstos se fundamenten en la Constitución. Ni mucho menos las presuntas incongruencias con interpretaciones hechas en casos similares o aparentemente similares son causales de nulidad.

Y, además tratándose de nulidad de sentencias de tutela (en revisión por la Corte), la violación al debido proceso debe darse dentro de la sentencia, no antes, porque ello implicaría una revisión a la revisión y, aun habiéndose dictado el fallo hay que evitar que en la práctica, se convierta la nulidad en una tutela a la sentencia”.

Obsérvese como la Corte de manera preventiva dice explícitamente que la nulidad no es un sinónimo de recurso, y que no se puede llegar a pensar en Colombia en una tutela contra sentencias de la Corte Constitucional.

En el auto 33 de $1995^{11}$, por cuarta ocasión en la corta historia de vida de la Corte se presentó una solicitud de nulidad, se hace una explicación de cuándo pro-

\footnotetext{
$9 \quad$ Auto del 26 de julio de 1993, M.P. Jorge Arango Mejía.

10 Auto del 3 de noviembre de 1994, M.P. Alejandro Martínez Caballero.

11 Auto del 22 de junio de 1995, M.P. José Gregorio Hernández Galindo.
} 
cede la solicitud de nulidad, que constituye un auto hito ${ }^{12}$ : "Se trata de situaciones jurídicas especialísimas y excepcionales, que tan sólo pueden provocar la nulidad del proceso cuando los fundamentos expuestos por quien la alega muestran, de manera indudable y cierta, que las reglas procesales aplicables a los procesos constitucionales, que no son otras que las previstas en los decretos 2067 y 2591 de 1991, han sido quebrantadas, con notoria y flagrante vulneración del debido proceso. Ella tiene que ser significativa y trascendental, en cuanto a la decisión adoptada, es decir, debe tener unas repercusiones sustanciales, para que la petición de nulidad pueda prosperar".

\subsubsection{Presupuestos formales de procedencia ${ }^{13}$}

Bajo el entendido de que la solicitud de nulidad de una sentencia de la Corte Constitucional sólo procede de manera excepcional, ésta debe cumplir los siguientes requisitos formales:

La solicitud debe presentarse dentro de los tres (3) días siguientes a la notificación de la sentencia adoptada por la Corte. En consecuencia, vencido este término, se entiende que todos los vicios que podrían derivar en la nulidad del fallo, quedan automáticamente saneados ${ }^{14}$.

Sin embargo, si el vicio alegado se funda en situaciones ocurridas con anterioridad a la adopción del fallo, en virtud de lo dispuesto en el artículo 49 del Decreto 2067 de 1991, la solicitud de nulidad deberá presentarse antes de proferida la sentencia. En caso que las partes que intervinieron en el proceso constitucional no eleven petición en ese sentido dentro de la oportunidad prevista, se entiende que pierden su legitimidad para invocar la nulidad posteriormente ${ }^{15}$.

12 Sobre el concepto de sentencia hito, ver: LÓPEZ MEDINA, Diego Eduardo. El Derecho de los Jueces. Segunda edición. Bogotá: LEGIS, 2011. p. 163.

13 Auto 301 del 5 de noviembre de 2008, M.P. Jaime Araujo Rentería.

14 Sobre el particular, en el Auto A-031A de 2002, M.P Eduardo Montealegre Lynett, esta Corporación sostuvo: "[V]encido en silencio el término de ejecutoria cualquier eventual nulidad queda automáticamente saneada, no sólo por la carencia de legitimidad para pedirla, sino, además, por las siguientes razones: (i) en primer lugar, atendiendo el principio de seguridad jurídica y de necesidad de certeza del derecho (Corte Constitucional, Auto 232 del 14 de junio de 2001 MP. Jaime Araujo Rentería); (ii) en segundo lugar, ante la imposibilidad presentar acción de tutela contra las providencias de tutela (Cfr. Corte Constitucional, Sentencia SU-1219 de 2001 MP. Manuel José Cepeda). Y finalmente, (iii) porque es razonable establecer un término de caducidad frente a las nulidades de tutela, si incluso esa figura aplica en las acciones de inconstitucionalidad por vicios de forma (Según el artículo 242-3 de la Carta, las acciones por vicios de forma caducan en el término de un año contado a partir de la publicación del respectivo acto)." (Negrilla fuera del texto original).

$15 \mathrm{Al}$ respecto, se puede consultar el auto del día 20 de febrero de 2002, M.P. Jaime Araujo Rentería. 
Pero, si el vicio se deriva de la propia sentencia, la solicitud de nulidad deberá ser presentada dentro de los tres (3) días siguientes a su notificación ${ }^{16}$.

Las solicitudes de nulidad de las sentencias proferidas por la Corte Constitucional deben haber sido presentadas por quien tenga legitimidad para hacerlo, esto es, quien haya sido parte en el proceso ${ }^{17}$.

\subsubsection{Presupuestos materiales de procedencia ${ }^{18}$}

Cumplidos los anteriores requisitos formales, la solicitud de nulidad de una sentencia proferida por la Corte Constitucional debe encontrarse ajustada a los siguientes límites y argumentos:

Quien invoca la nulidad tiene la carga de demostrar, con base en argumentos serios y coherentes, que la sentencia vulnera el derecho al debido proceso. Por tanto, dado que el incidente de nulidad no es una nueva oportunidad para discutir los problemas jurídicos planteados durante el trámite constitucional, no son suficientes razones o interpretaciones diferentes a las indicadas en la sentencia, que obedezcan al disgusto e inconformidad del solicitante con la decisión.

La solicitud de nulidad no puede estar encaminada a reabrir el debate probatorio decidido por la Corte Constitucional en su sentencia. Esto, por cuanto es claro que el incidente de nulidad no constituye una nueva instancia o un recurso mediante el cual se pueda proferir una nueva decisión sobre la controversia jurídica dirimida en la sentencia.

Como se indicó anteriormente, el fundamento esencial de la solicitud de nulidad debe ser la afectación del derecho al debido proceso. En este sentido, es claro que los criterios de forma, como la redacción, el estilo y la argumentación utilizada

16 Auto del día 13 de febrero de 2002, M.P. Marco Gerardo Monroy Cabra. Al respecto, en esta providencia, la Corte señaló:

“a). Las nulidades que puedan ocurrir durante el trámite del proceso de constitucionalidad o del proceso de tutela, sólo pueden alegarse antes de la sentencia respectiva. Si no se invocan en esa oportunidad, las partes pierden legitimación para hacerlas una vez proferida la sentencia. b). La nulidad originada en la sentencia se debe alegar en forma fundamentada durante el término de notificación de la sentencia en materia de constitucionalidad, y dentro de los tres días siguientes de haberse proferido y comunicado en materia de tutela. c). La nulidad en la sentencia puede ocurrir por vicios o irregularidades en la misma sentencia, y por violación al debido proceso. En sentencias de tutela se pude presentar, por ejemplo, cuando una Sala de Revisión dicta una sentencia con desconocimiento de un precedente jurisprudencial adoptado en Sala Plena. d). Si la nulidad consiste en irregularidades en la notificación de la sentencia, o en acto posterior a la misma, la nulidad afecta dicho acto pero no la sentencia. e. La nulidad no es un medio idóneo para reabrir el debate probatorio, o para revisar la sentencia ya que ello no está establecido en la ley, ni constituye una nueva instancia, ni tiene la naturaleza de recurso."

17 Al respecto, se pueden consultar los autos A-178 de 2007, A-301 de 2006, A-292 de 2006 y Ade 2006. Las notas 13 a 16 son de la cita.

Auto 301 del 5 de noviembre de 2008, MP Jaime Araújo Rentería. 
en la sentencia, no constituye una afectación del derecho al debido proceso. Por consiguiente, de conformidad con la jurisprudencia constitucional, la afectación de este derecho debe ser cualificada", esto es, "ostensible, probada, significativa y trascendental, es decir, que tenga repercusiones sustanciales y directas en la decisión. $^{20 " ~(N e g r i l l a ~ y ~ s u b r a y a ~ d e l ~ t e x t o ~ o r i g i n a l) . ~}$

$\mathrm{Al}$ respecto, la Corte ha considerado que existe afectación del derecho al debido proceso, por ejemplo, en los siguientes $\operatorname{casos}^{21}$ :

“- Cuando una Sala de Revisión cambia la jurisprudencia de la Corte. El artículo 34 del decreto 2591 de 1991 establece que todo cambio de jurisprudencia debe ser decidido por la Sala Plena; en consecuencia, si una de las salas de revisión se apropia de esa función, se extralimita en el ejercicio de sus competencias con una grave violación al debido proceso. ${ }^{22}$ Sin embargo, no toda discrepancia implica cambio de jurisprudencia, puesto que ella debe guardar relación directa con la ratio decidendi de la sentencia de la cual se predica la modificación, ${ }^{23}$ en caso contrario, '[L]as situaciones fácticas y jurídicas analizadas en una sentencia de una Sala de Revisión y que sirven de fundamento para proferir un fallo son intangibles, porque son connaturales a la libertad, autonomía e independencia que posee el juez para evaluarlas y juzgarlas'"24.

- Cuando una decisión de la Corte es aprobada por una mayoría no calificada según los criterios que exige la ley ${ }^{25}$.

- Cuando existe incongruencia entre la parte motiva de una sentencia y la parte resolutiva de la misma, que hace anfibológica o ininteligible la decisión adoptada; ${ }^{26}$ igualmente, en aquellos eventos donde la sentencia se contradice abiertamente, o cuando la decisión carece por completo de fundamentación.

- Cuando la parte resolutiva de una sentencia de tutela da órdenes a particulares que no fueron vinculados o informados del proceso ${ }^{27}$.

- Cuando la sentencia proferida por una Sala de Revisión desconoce la cosa juzgada constitucional, pues ello significa la extralimitación en el ejercicio de sus atribuciones"28 (Negrilla fuera del texto original).

\footnotetext{
19 Auto A-025 de 2007, M.P. Jaime Córdoba Triviño.

20 Auto A-031A de 2002, M.P. Eduardo Montealegre Lynett.

21 Ibídem. Así mismo, se puede consultar el auto A-006 de 2008, M.P. Jaime Araújo Rentería.

22 Cfr. entre muchos otros, auto 052 de 1997. M.P. Fabio Morón Díaz, auto 003A de 1998, M.P. Alejandro Martínez Caballero, auto 082 de 2000 M.P. Eduardo Cifuentes Muñoz.

23 Cfr. Auto 053 de 2001 M.P. Rodrigo Escobar Gil.

24 Corte Constitucional, auto 105A de 2000 M.P. Antonio Barrera Carbonell

25 Cfr. Auto 062 de 2000, M.P. José Gregorio Hernández Galindo.

26 Cfr. Auto 091 de 2000, M.P. Antonio Barrera Carbonell.

27 Cfr. Auto 022 de 1999, M.P. Alejandro Martínez Caballero

28 Cfr. Auto 082 de 2000, M.P. Eduardo Cifuentes Muñoz.
} 
Adicionalmente, la Corte ha contemplado la configuración de una causal de nulidad de sus sentencias cuando, de manera arbitraria, se dejan de analizar asuntos de relevancia constitucional que tienen efectos transcendentales para el sentido de la decisión" 29 (negrita y cursiva del texto).

\subsection{Caso hito}

Este caso tiene su origen en la presentación de una demanda de inconstitucionalidad cuya pretensión fue:

"La pretensión de la demanda es que se declare la inconstitucionalidad exclusivamente de las expresiones subrayadas de las siguientes disposiciones legales que regulan la prescripción extintiva en Derecho del Trabajo y la Seguridad Social y las demás que tengan unidad normativa:

1. Código Procesal del Trabajo y de la Seguridad Social, artículo 151: "Las acciones que emanen de las leyes sociales prescribirán en tres años, que se contarán desde que la respectiva obligación se haya hecho exigible. El simple reclamo escrito del trabajador, recibido por el patrono, sobre un derecho o prestación debidamente determinado, interrumpirá la prescripción pero sólo por un lapso igual". (Subrayado fuera de texto).

2. Código Sustantivo del Trabajo, artículo 488: "Las acciones correspondientes a los derechos regulados en este código prescriben en tres (3) años, que se cuentan desde que la respectiva obligación se haya hecho exigible, salvo en los casos de prescripciones especiales establecidas en el Código Procesal del Trabajo". (Subrayado fuera de texto)" (...) (cursiva y subrayado del texto)".

Vistas las normas que el accionante considera inconstitucionales, se hace notorio a simple vista que su pretensión vaya dirigida a que la Corte se pronuncie sobre si es o no constitucional el momento preestablecido por la ley en el cual empieza a contar la prescripción.

Como razones de la violación, el ciudadano explica: “1. Las disposiciones legales demandadas regulan la prescripción extintiva en Derecho Laboral y Seguridad Social. No cuestiono la prescripción de las obligaciones del empleador y correlativamente los derechos del trabajador, pues la prescripción es una institución necesaria en un Estado social de derecho para garantizar la seguridad jurídica. No obstante, consagrada la institución de la prescripción en Derecho Laboral y Seguridad Social, el dilema que se presenta es sobre el inicio del término de prescripción”.

Y concluye: "Por consecuencia, se vulneran los artículos 53 y 93 de la Constitución Política, y parcialmente los artículos 151 del Código Procesal del Trabajo y de la Seguridad Social, 488 del Código Sustantivo del Trabajo, 41 del Decreto 3135 de 1968, y 102 del Decreto 1848 de 1969 son contrarios a la Constitución Política" (subrayado fuera de texto).

29 Auto A- 031A de 2002, M.P. Eduardo Montealegre Lynett. Las notas 18 a 28 son de la cita. 
En conclusión, se observa que indubitablemente la pretensión del accionante es única y exclusivamente el estudio de constitucionalidad del momento en el cual se empieza a contar la prescripción laboral.

La Corte Constitucional por medio de la sentencia C-916 de $2010^{30}$ consideró: "2.2. Pretensión: El actor solicita se declare la inexequibilidad de los apartes subrayados contentivos en las normas demandadas, por considerarlos que vulneran los artículos 1, 2, 5, 25, 48, 53 y 93 de la Constitución Política; y el artículo 12 numeral 2 del Convenio 95 sobre la protección del salario de la Organización Internacional del Trabajo, de 1949" (negrita del texto).

Sin embargo, en las consideraciones de la sentencia, la Corte define el problema constitucional así: "Esta Corporación deberá determinar ¿Si el establecimiento de un término trienal de prescripción de la acción laboral -contado a partir de la fecha en que la respectiva obligación se haya hecho exigible- violenta de alguna forma el derecho al trabajo?".

Se debe aclarar, que hasta esta instancia, la Corte aún mantiene el núcleo de la pretensión del accionante. No obstante, le agrega el "término trienal de prescripción de la acción laboral".

La Corte en la consideración 4, numeral que titula "Unidad normativa completa" establece en el último párrafo:
“4.2. En el presente caso se demandó la expresión “...que se cuentan desde que la respectiva obligación se haya hecho exigible” redactada con mínimas variaciones en ambos cuerpos normativos (Art. 488 CST y art. 151 CPTSS). Dicho aparte demandado no posee identidad propia y carece de contenido unívoco; esto es no se entiende que es lo que se cuenta desde que la obligación es exigible. En conclusión, es indispensable formular la proposición jurídica completa, es decir aquella que explica a qué tipo de obligaciones se refiere la expresión acusada y el término que debe contarse desde que dicha obligación es exigible;..." (Cursiva del texto)".

Con el anterior argumento, la Corte -de manera apresurada en su consideración 5 titulada "Cosa Juzgado Constitucional" - concluye: "5.1. Mediante Sentencia C- 072 de 1994, esta Corte estudió el artículo 505 del Decreto 2663 de 1950 (Código Sustantivo del Trabajo), hoy artículo 488 y el artículo 151 del Decreto Ley 2158 de 1948 (Código Procesal del Trabajo y la Seguridad Social.) En dicha ocasión, el demandante argumentaba la violación de los artículos 1, 2, 4, 13, 17, 29, 53, 58, 150, 215 y 229 de la Constitución Política".

Y concluyó:

"Así las cosas, y con base en los anteriores planteamientos, se declaró la exequibilidad de las normas analizadas. Por consiguiente, considera esta

30 Sentencia del 16 de noviembre de 2010, M.P. Mauricio González Cuervo. 
Corporación que en el presente caso y respecto de los contenidos normativos acusados de los artículos 488 y 151 del Código Sustantivo del Trabajo y del Código Procesal del Trabajo y la Seguridad Social, respectivamente; ha operado el fenómeno jurídico de la Cosa Juzgada Constitucional" (subrayado fuera de texto).

Por último es menester hacer cita de la consideración 5.3 de la precitada sentencia con la finalidad de aclarar la postura de la Corte Constitucional en este caso:

“5.3. En suma, la Sentencia C- 072 de 1994, analizó las disposiciones normativas acá acusadas (art. 488 y art. 151) del Código Sustantivo de Trabajo y del Código Procesal del Trabajo y la Seguridad Social, respectivamente; y lo realizó bajo las mismas controversias jurídicas planteadas en la presente demanda. Por tal razón, esta Corte declarará estarse a lo resuelto en la Sentencia C-072 de 1994 que declaró exequibles el artículo 488 del Código Sustantivo de Trabajo y el artículo 151 del Código Procesal de Trabajo".

Lo increíble del caso en estudio es que en la sentencia C-72 de 1994la pretensión del demandante era la inconstitucionalidad de la prescripción, para el demandante dicho término era muy corto y, por consecuencia, vulneraba algunas disposiciones de la Constitución Política.

Como se observa por simple lógica, dicha pretensión es diametralmente opuesta a la pretensión resuelta en la sentencia C-916 de 2010; que se centró en la inconstitucionalidad del momento en cual se empieza a contar el término de la prescripción laboral.

El ciudadano inconforme con la decisión tomada por la Corte Constitucional, presentó una solicitud de nulidad (estudiada en este trabajo en precedencia, 1.1).

La Corte ha dicho que cuando se presente solicitudes de nulidad contra una sentencia de constitucionalidad "C-"se debe hacer ante el magistrado ponente que redactó dicha sentencia. En el caso sub-examine el magistrado encargado de redactar la ponencia y, por consiguiente, conocer de la solicitud de nulidad fue Mauricio González Cuervo.

El accionante sustentó su inconformidad en el memorial que contiene la solicitud así: "1. En la demanda no cuestioné la existencia de la institución de la prescripción laboral y de seguridad social, sino únicamente el momento desde que inicia el término de prescripción; las disposiciones legales fueron demandadas parcialmente y sólo en las expresiones relativas al inicio del término".

Y afirmó que la nulidad debía prosperar porque: "4. La Corte resolvió algo diferente de lo pedido, desconociendo la pretensión y las razones de la violación, contrario al principio de congruencia (...) Por consiguiente, la violación del debido proceso (CP, art. 29) es "ostensible, probada, significativa y trascendental" (Corte Constitucional, auto 31A del 30 de abril de 2002, M.P. Eduardo Montealegre Lynett), porque el principio de congruencia es un elemento del debido proceso...." 
Por auto 73 de $2011^{31}$, la Corte Constitucional decidió la solicitud de nulidad negándola así: "Al respecto debe manifestar esta Corporación que la petición presentada en momento alguno se enmarca dentro de los presupuestos teóricos esbozados con anterioridad. En efecto, el solicitante está inconforme por el hecho de que la Corte Constitucional se hubiere pronunciado respecto de la prescripción del artículo acusado en la demanda de constitucionalidad y que produjo como decisión estarse a lo resuelto en la Sentencia C-072 de 1994. Dicha apreciación subjetiva del solicitante no demuestra ninguna de las causales de nulidad. La Corte entendió con la demanda que se cuestionaba - en primer momento como se verá adelante - el término de prescripción anotado y por ende falló al respecto; descartando entonces la supuesta falta de congruencia" (subrayado fuera de texto).

De la parte subrayada y en negrilla se infiere que la Corte Constitucional entendió que la pretensión del ciudadano se centraba en la declaratoria de inconstitucionalidad del término de prescripción y, por consecuencia, se pronunció sobre el punto.

Con el mayor respeto que le es dado por su invaluable labor a la Corte Constitucional, en el caso en estudio, evidentemente le asiste la razón al demandante. Lo anterior toda vez que la Corte entendió de manera errada la pretensión, haciendo un estudio de constitucionalidad por unos argumentos que no fueron esbozados $\mathrm{y}$, por consiguiente, dictando una sentencia que en su decisum declara estarse a lo resuelto en la sentencia C-72 de 1994.

Como se observa en el presente caso, la solicitud de nulidad no logró su objeto, que no es otro sino la real aplicación de derechos fundamentales, en concreto, el debido proceso. Entonces, si la solicitud de nulidad que es el mecanismo ordinario procedente, qué puede hacer el ciudadano a quien a pesar de tener razón, la Corte le viola un derecho fundamental. Consideramos que puede acudir a la petición de tutela y al Sistema Interamericano de Derechos Humanos.

\section{Petición de tutela}

\section{1 definición}

La Constitución Política de 1991 tiene como principal característica la de ser una Carta antropocéntrica, el hombre es el núcleo fundante de la sociedad y todas las instituciones deben girar buscando el bienestar de él.

Partiendo de la anterior premisa, y preocupados por la efectiva aplicación de los derechos constitucionales fundamentes, se creó un mecanismo llamado acción, o mejor, petición de tutela. La petición de tutela es un medio jurídico para la protección y garantía de derechos fundamentales. Está consagrada en el art. 86 así: “Toda

$31 \quad$ Auto del 27 de abril de 2011, M.P. Mauricio González Cuervo. 
persona tendrá acción de tutela para reclamar ante los jueces, en todo momento y lugar, mediante un procedimiento preferente y sumario, por sí misma o por quien actúe a su nombre, la protección inmediata de sus derechos constitucionales fundamentales, cuando quiera que éstos resulten vulnerados o amenazados por la acción o la omisión de cualquier autoridad pública..." (Subrayado fuera de texto).

Nadie puede discutir la calidad de autoridad pública de la Corte Constitucional, por lo que podría hablarse de una excepcional tutela contra sus providencias, sin embargo surgen una gran cantidad de interrogantes: 1) ¿Quién sería el juez competente para conocer de la tutela contra la Corte Constitucional, 2) En sede de revisión, ¿podría la Corte Constitucional ser parte y juzgador? y 3) ¿Se puede armar una cadena interminable de tutelas sobre un mismo conflicto de intereses?

\subsection{Competencia cuando el demandado es la Corte Constitucional}

Para encontrar respuesta al interrogante acerca de cuál juez sería competente para conocer de una tutela en el caso que el supuesto sujeto lesionador de derechos fundamentales sea la Corte Constitucional es menester remitirse a la normativa que reglamenta esta temática.

Sobre la petición de tutela, son tres los decretos que reglamentan su procedimiento: Decreto 2591 de 1991, Decreto 306 de 1992 y Decreto 1382 de 2000.

Respecto a la competencia, el Decreto 2591 establece el capítulo II (arts. 37-41) para reglamentar esta figura procesal. En el art. 37 se establece una competencia genérica habida cuenta que se reglamenta una competencia para todas las tutelas, sin hacer ningún tipo clasificación. El art. 37 dice: "Primera instancia. Son competentes para conocer de la acción de tutela, a prevención, los jueces o tribunales con jurisdicción en el lugar donde ocurriere la violación o la amenaza que motivaren la presentación de la solicitud".

La competencia genérica utiliza como criterio el factor territorial para su competencia al establecer que será competente el juez dónde ocurrió o está ocurriendo la actuación violatoria del derecho fundamental.

Años después se expidió el Decreto 1382, por el cual se establecen reglas para el reparto de la acción de tutela. Este Decreto nació debido a que por la distribución geográfica de los despachos judiciales, podían existir varios juzgadores con la posibilidad de conocer una acción de tutela. Debido al silencio del Decreto 2591 sobre reglas de competencia para jueces de una misma entidad territorial, se vio la necesidad de regular la forma de reparto de las acciones de tutela, con el fin de racionalizar y desconcentrar el conocimiento de las mismas.

El Decreto se compone por 6 artículos. Las reglas pertinentes para el tema de investigación de este trabajo son las siguientes:

Regla 1 (R1): "Las acciones de tutela que se interpongan contra cualquier autoridad pública del orden nacional, salvo lo dispuesto en el siguiente inciso, serán 
repartidas para su conocimiento, en primera instancia, a los tribunales superiores de distrito judicial, administrativos y consejos seccionales de la judicatura" (Decreto 1382 de 2000, art. 1, núm. 1).

Regla 2 (R2): "Cuando la acción de tutela se promueva contra un funcionario o corporación judicial, le será repartida al respectivo superior funcional del accionado" (Ibídem., art. 1, núm. 2, inc. 1).

Regla 3 (R3): "Lo accionado contra la Corte Suprema de Justicia, el Consejo de Estado o el Consejo Superior de la Judicatura, Sala Jurisdiccional Disciplinaria, será repartido a la misma corporación y se resolverá por la Sala de Decisión, sección o subsección..." (Ibídem., art. 1, núm. 2, inc. 2).

Nótese que de la literalidad de la normativa en comento y de las reglas inferidas, nada se dice sobre la posibilidad que se presente una tutela contra la Corte Constitucional. Es decir, hay un silencio o vacío normativo. Entonces, dicho silencio se puede tomar de dos formas: como una omisión legislativa o como una negativa implícita por parte del legislador de que esa situación, petición de tutela contra la Corte Constitucional se pueda presentar.

Si se asume la primera, se debe acudir a otras fuentes del derecho para llenar el vacío legal producto de la omisión legislativa. Si se asume la segunda, bastará con esbozar argumentos como la cosa juzgada constitucional para sustentarla.

Este trabajo parte de la base de que la estructura normativa de un Estado debe propender por la efectiva aplicación de los derechos que le asisten a sus asociados. Por esa razón, se toma como correcta la primera posición.

La R1 sirve como regla de competencia si alguna persona desea presentar una petición de tutela contra la Corte Constitucional. Esto debido a que la Corte es una autoridad pública de orden nacional, dicho de otra manera, el supuesto de una acción contra el Tribunal Constitucional satisface cabalmente los presupuestos de la regla.

La R2 podría eventualmente como regla a aplicar para saber qué juez es competente en el supuesto en estudio. Sin embargo, saldría la interrogante sobre quién es el superior jerárquico de la Corte Constitucional. En Colombia no existe ningún argumento que sustente una respuesta a esa interrogante. Por lo tanto, se considera que la Corte no posee un superior. Como conclusión la regla no es aplicable.

La R3 literalmente no sirve como regla de competencia. Lo anterior porque el supuesto normativo no contempla la posibilidad de que la tutela se presente contra la Corte Constitucional. Pero, se podría aplicar en virtud de que los sujetos pasivos de la acción de tutela que establece la regla son homólogos al Tribunal Constitucional (la Corte Suprema de Justicia es el máximo órgano de la jurisdicción ordinaria, el Consejo de Estado el máximo órgano de la jurisdicción administrativa, el Consejo Superior de la Judicatura es el máximo órgano de ad- 
ministración, gestión y control de la Rama Judicial y la Corte Constitucional es el máximo órgano de la jurisdicción constitucional).

Otra solución sería la aplicación de la excepción de inconstitucionalidad por parte del juez de instancia del Decreto 1382 de 2000, dándole aplicación al art. 86 de la Constitución Política. La opción puede ser válida, sin embargo, quedaría supeditada a la discrecionalidad del juez en particular y únicamente solucionaría un caso en concreto, no dando una solución general.

Las reglas aparentemente aplicables serían la $\mathrm{R} 1$ y la $\mathrm{R} 3$, pero es necesario encontrar la que se ajuste más a la normativa colombiana. Debido a que no existe norma especial para darle una solución al caso planteado se deben aplicar las reglas generales, ya que hacer una aplicación analógica de la R3 sería crear una nueva norma. En ese orden de ideas, lo correcto es aplicar la R1 como regla general ${ }^{32}$.

\subsection{Petición de tutela y cosa juzgada constitucional}

Del fragmento resaltado se extrae que una de las características de la petición de tutela es su calidad de protectora de violaciones cometidas por las autoridades públicas en Colombia. Es decir, que por mandato constitucional, todo hecho violatorio de un derecho fundamental producto de las actuaciones de autoridades públicas podrá ser detenido por medio de un procedimiento preferente y sumario iniciado por la presentación de una petición de tutela.

La Corte Constitucional por pertenecer a la Rama Judicial del Poder Público, según lo preceptuado por los arts. 113 y 241 de la Constitución Política, se considera indiscutiblemente como una corporación colegiada que administra justicia de carácter público.

Ahora, del aparte normativo citado, también se desprende que cualquier Juez de la República podría conocer de la acción, juzgar el hecho y proferir una sentencia resolviendo la problemática planteada. El art. 37 del Decreto 2591 de 1991 establece: "Son competentes para conocer de la acción de tutela, a prevención, los jueces o tribunales con jurisdicción en el lugar donde ocurriere la violación o la amenaza que motivaren la presentación de la solicitud".

Sin embargo, se debe aclarar que los jueces que conocen de la petición de tutela hacen parte de la jurisdicción constitucional debido a que se les ha asignado la función de emitir providencias para aplicar directamente derechos constitucionales fundamentales.

Según el art. 241 de la Constitución Colombiana y el art. 43 de la Ley 270 de 1996, la Corte Constitucional es el tribunal de cierre de la jurisdicción constitucional; si bien es cierto que no se dice de manera explícita, se puede inferir de la

32 Auto 093 de 2002, M.P. Marco Monroy Cabra, conflicto de competencia ICC-322. 
normativa mencionada. Como corolario se tiene que la última palabra en temas de acción de tutela recae en la Corte Constitucional.

De lo estudiado hasta ahora se extraen dos proposiciones independientes. Por un lado, la petición de tutela procede contra toda autoridad pública (como la Corte Constitucional) que en sus actuaciones viole algún derecho fundamental, por el otro se tiene que la Corte Constitucional como órgano de cierre tiene la última palabra en temas de petición de tutela.

Empero, estas proposiciones pueden entrar en colisión si se plantea uno situación fáctica hipotética: la Corte Constitucional, en sede de revisión, observa la falta de notificación al sujeto pasivo de la tutela, el cual fue condenado en primera y segunda instancia. La falta de notificación producto de causas como negligencia, exceso de trabajo o errores en criterios jurídicos de la Sala de Revisión; la Corte confirma la tutela no aplicando derechos fundamentales como el de defenderse y contradecir las actuaciones que vayan en contra de lo intereses de un particular. ¿El ciudadano a quien se le ha violado el derecho de defensa y contradicción cuenta con la acción de tutela para hacerlos efectivos? Si aplicamos un razonamiento silogístico de la primera proposición se llegaría a la conclusión valida de que sí, veamos: primera premisa: la tutela procede contra toda autoridad pública (...); segunda premisa: la Corte Constitucional en una autoridad pública; y conclusión: la tutela procede contra la Corte Constitucional.

La segunda proposición no permite la conclusión antes mencionada. Lo anterior, toda vez que como tribunal de cierre, la Corte Constitucional tiene la última palabra sobre la interpretación y aplicación de los postulados constitucionales como son los derechos fundamentales. Por tal razón, pedirle a un juez de inferior jerarquía que revise los fallos de su superior contraría la forma como está diseñada la estructura de la jurisdicción constitucional.

Entonces, para asumir una postura entre esta disyuntiva se va a partir de una premisa filosófica no verificable: "todos los hombres son falibles". Para el tema en estudio, la Corte Constitucional por estar compuesta por hombres (nueve magistrados), puede cometer errores. Esos errores, en algunos casos, tienen repercusiones sustanciales en los derechos fundamentales de las partes del litigio.

Por tal motivo, y tomando como base el carácter antropocéntrico de la Constitución, la petición de tutela debe ser un mecanismo para proteger derechos, sin discriminación de quién sea el sujeto lesionador de los derechos. Aunque se debe aclarar que la conclusión de que la petición de tutela es un mecanismo que procede contra las providencias de la Corte Constitucional colombiana es excepcional; la regla general debe ser la negativa, es decir, las providencias emitidas por el tribunal en comento hacen tránsito a cosa juzgada constitucional, pero siempre que no violen derechos fundamentales. Refiriéndose a esta idea el profesor Roberto Omar Berizonce manifiesta: "El tan delicado equilibrio entre la seguridad jurídica y la justicia de las decisiones parece requerir ciertos ajustes. No se trata de minar 
imprudentemente la autorictas reijudicata, sino en todo caso de reexaminar sus fronteras para en su caso, producir un sutil corrimiento de sus confines en aras de asegurar la virtualidad de ciertos principios fundantes que emanan del bloque axiológico de la Constitución, y en particular la garantía de la eficaz prestación de los servicios de justicia"33.

La posibilidad de que sea procedente la petición de tutela contra una providencia judicial proferida por el máximo órgano de la jurisdicción constitucional no soslaya o usurpa la función que por mandado constitucional le fue asignada - proteger la supremacía e integridad de la constitución-. La interpretación que hace la Corte debe acatarse. No obstante, la corte puede violar derechos realizando actos procesales de manera equivocada, como una indebida notificación, por poner un ejemplo. En el caso que se analizó en materia laboral ${ }^{34}$, quedo demostrado que la corte modificó arbitrariamente la pretensión del accionante, por lo que la tutela se hace procedente no para usurpar la función de la Corte Constitucional -sería errado afirmar que un juez de inferior jerarquía puede desacatar la doctrina constitucional integradora ${ }^{35}-$, sino para que se le respete el derecho al debido proceso al accionante, y en consecuencia se le ordene a la Corte conocer la verdadera pretensión alegada.

\subsection{Caso hito ${ }^{36}$}

Hechos del caso y actuación procesal: un proceso hipotecario iniciado contra Paula Jhoanna Rodríguez y Nicolás Eduardo Rodríguez Sierra nacido de la financiación de vivienda UPAC, había perdido un bien inmueble, el hipotecario, y que más tarde fue comprado por Abraham Merchán Corredor, acto contractual que fue registrado. Paula Jhoanna Rodríguez presentó petición de tutela con fundamento en los derechos otorgados por la Sentencia C-955 de 2000 de la Corte Constitucional a los deudores del crédito UPAC, frente a lo cual, para el caso la Corte Constitucional, ordenó la cancelación del registro y la restitución del bien inmueble al favor de Paula Johanna Rodríguez y de Nicolás Eduardo Rodríguez Sierra ${ }^{37}$.

33 BERIZONCE, Op. cit. p. 101.

34 Ver en este artículo: 2.4 Caso hito.

35 "Respetar el precedente constitucional para quienes administran justicia no es una opción más dentro de nuestro complejo sistema jurídico, sino un deber, especialmente porque es a través del ejercicio de esta actividad que se asegura de manera definitiva la eficacia de los derechos constitucionales". Corte Constitucional, T-292 del año 2006.

36 Consejo de Estado, Sala de lo Contencioso Administrativo, Sección Segunda, Subsección A, sentencia de tutela de segunda instancia del 11 de junio de 2008, exp. 25000232500020080032101, M.P. Gustavo Eduardo Gómez Aranguren.

37 Análisis Jurisprudencial: pronunciamiento del Consejo de Estado sobre la Tutela contra Tutela. Mónica Yineth Díaz Aya. Universidad Externado de Colombia. Revista Derecho del Estado, núm. 21, diciembre de 2008. Disponible en http://revistas.uexternado.edu.co/index. $\mathrm{php} /$ derest/issue/view/48 
El accionante Abraham Merchán Corredor consideró que dentro del trámite de la petición de tutela hubo nulidad insanable por violación del derecho de defensa, porque en las dos instancias fue vinculado el Banco Central Hipotecario, pero no se vinculó a Central de Inversiones S.A., cuando ésta era el cesionario del crédito cobrado, lo que imposibilitó su oportunidad de hacer parte en las instancias de la acción de tutela, y ya en sede de revisión, aunque por medio de auto del 27 de marzo de 2007 se dispuso la vinculación del adjudicatario CISA, la notificación omitió enterar en forma completa los hechos y omisiones que motivaban la reclamación constitucional; situación por la que, pese a ser puesta en conocimiento de la Corte Constitucional, no se logró respuesta ni pronunciamiento alguno. Por este motivo, el Abraham Merchán Corredor presentó petición de tutela, que en primera instancia fue decidida por el Tribunal Administrativo de Cundinamarca emitiendo una providencia inhibitoria en el sentido que declara que tal acción es improcedente toda vez que la sentencias de la Corte Constitucional hacen tránsito a cosa juzgada constitucional según el art. 243 constitucional y el art. 49, inc. 1 del Decreto 2067 del 1991.

Dicha decisión fue objeto de impugnación, por lo cual conoció en segunda instancia la Sección Segunda, Subsección "A" del Consejo de Estado, actuando como Consejero Ponente Gustavo Gómez Aranguren decidiendo revocar la providencia del 7 de abril de 2008 proferida por el A-quo y denegar el amparo del derecho a la vivienda digna de Abraham Merchán Corredor.

Lo interesante de esta providencia se centra en las razones por las cuales el máximo órgano de la jurisdicción contenciosa administrativa revocó la decisión del tribunal y conoció de fondo la tutela.

En la parte considerativa de la mencionada sentencia se consideró: "En este sentido, la violación de los derechos fundamentales y el correlativo deber de protección otorgado por el Constituyente al poder judicial, no diferencia el elemento activo del quebranto del derecho fundamental, (...) "La circunstancia de que el poder judicial haya sido investido con la facultad de protección a los derechos fundamentales, no le hace inmune a las lesiones en las que este mismo poder pueda incurrir por sus acciones y omisiones". Sobre este punto termina diciendo: "Se precisa, que para esta Sala cualquier conculcación o vulneración de un derecho fundamental, habilita la injerencia del juez constitucional, sin importar la calidad del sujeto de quien provenga el hecho dañoso". El Consejo de Estado toma como premisas las estudiadas en este trabajo, es decir, el criterio filosófico inverificable de la falibilidad de los seres humanos y el postulado constitucional del art. 86.

Las razones por las cuales el Consejo de Estado se decidió a estudiar la tutela fueron las siguientes: "De importancia resulta afirmar, que de conformidad con lo expresado en párrafos anteriores, esta Sala considera procedente la presente acción de tutela al considerar que: 1) Todas las providencias judiciales incluso las proferidas por la Corte Constitucional son objeto de amparo constitucional; 2) no 
cuenta el actor con otro medio de defensa judicial por tratarse de una providencia proferida por un organismo de cierre; 3 ). Porque pese a la prohibición de la procedencia de tutela contra fallos de tutela, tal prohibición no aplica cuando quien instaura la nueva acción conjuga inescindiblemente dos presupuestos básicos: el primero, no haber hecho parte dentro del proceso de tutela y el segundo; haberse presentado vulneraciones de un derecho de categoría fundamental en razón del fallo, cuya protección dado su innegable urgencia, no permita ser reclamado por instancias diferentes a la acción de tutela".

De lo anterior se extrae que: a) El Consejo de Estado considera que la regla general que se debe aplicar es la prohibición de tutela contra sentencias de la Corte Constitucional. b) La regla excepcional es que si se puedan presentar peticiones de tutela contra sentencias de la Corte Constitucional, pero siempre que se den dos circunstancias: 1) No haber hecho parte dentro del proceso de tutela; y 2) haberse presentado vulneraciones de un derecho de categoría fundamental en razón del fallo.

En lo que tiene que ver con la competencia, en este caso se observa que la regla aplicada fue la R1, es decir, las acciones de tutela que se interpongan contra cualquier autoridad pública del orden nacional serán repartidas para su conocimiento en primera instancia a los Tribunales Superiores de Distrito Judicial, Administrativos y Consejos Seccionales de la Judicatura.

\section{Sistema Interamericano de Derechos Humanos}

En la Novena Conferencia Internacional Americana (Bogotá, Colombia, 1948) se adoptó la Resolución XXXI denominada "Corte Interamericana para Proteger los Derechos del Hombre", en la que se consideró que la protección de esos derechos debía "ser garantizada por un órgano jurídico, como quiera que no hay derecho propiamente asegurado sin el amparo de un tribunal competente". Finalmente, la Convención Americana sobre Derechos Humanos creó la Corte Interamericana de Derechos Humanos en 1969; sin embargo, el Tribunal no pudo establecerse y organizarse hasta que entró en vigor dicho tratado.

La Corte fue instalada oficialmente en su sede en San José, Costa Rica, el 3 de septiembre de 1979, y su Estatuto aprobado por la Asamblea General de la OEA celebrada en la Paz, Bolivia, en octubre de 1979, mediante la Resolución 448.

De conformidad con el art. 1 del Estatuto de la Corte, ésta es una institución judicial autónoma cuyo objetivo es la aplicación e interpretación de la Convención Americana sobre Derechos Humanos. Para el cumplimiento de dicho objetivo, la Corte tiene dos funciones: una función jurisdiccional y una función consultiva.

En lo que tiene que ver con la función jurisdiccional, para que pueda presentarse ante la Corte un caso contra un Estado parte, éste debe reconocer la competencia 
de dicho órgano. La declaración de reconocimiento de la competencia de la Corte puede ser hecha en forma incondicional para todos los cados o bien, bajo condición de reciprocidad.

Colombia por medio de la ley 16 de 1972 aprobó la Convención Americana sobre Derechos Humanos "Pacto de San José de Costa Rica", firmado en San José, Costa Rica, el 22 de noviembre de 1969. Con dicha aprobación por parte del Congreso colombiano y la posterior ratificación del ejecutivo, Colombia aceptó la jurisdicción internacional de la Corte Interamericana de Derechos Humanos.

\subsection{Control de convencionalidad vs. control de constitucionalidad}

El nacimiento de una justicia ajena al poder estatal lesiona la manera tradicional de ver el derecho. La función jurisdiccional que ejerce un tribunal internacional como la Corte Interamericana de Derechos Humanos obliga a replantear conceptos como el control constitucional que se entiende, o se entendía, lo hace el Estado; en palabras del argentino Néstor Pedro Sagües:

"Cabe observar que la implementación de una jurisdicción internacional de tipo supraestatal (...) ha hecho hacer el interrogante de un control transnacional o supraestatal de la constitucionalidad de normas y actos de un Estado local.

(...) De tal modo, se da una situación curiosa: la Constitución del Estado local cuenta con sus intérpretes "finales" nacionales; pero en ciertos rubros (en particular, derechos humanos) quien emitirá el último criterio -de darse los pasos procedimentales pertinentes- será el tribunal supranacional, quien por eso se convierte en sujeto control (último) del derecho o garantía constitucional estadual simultáneamente enunciando en el derecho regional o comunitario ${ }^{{ }^{38} 8}$.

En ejercicio de las funciones jurisdiccionales, se puede tomar dos posturas acerca de la naturaleza de los pronunciamientos de la Corte Interamericana. El primero, ala tradicionalista, afirma que el Tribunal se limita a estudiar los hechos que se le ponen a consideración y a concluir si efectivamente el Estado por medio de su actuación vulneró algún postulado de la normativa internacional. La otra, ala moderna, afirma que la Corte Interamericana por medio de sus providencias ejerce un verdadero control convencional homólogo a las funciones de los tribunales constitucionales internos, como el colombiano. Para esta última postura, la Corte Interamericana emite providencia interpretando la normativa internacional, que en virtud de la legitimidad que le asiste como intérprete de las nomas del Sistema Interamericano de Justicia son de obligatorio cumplimiento. Además, la Corte Interamericana puede y debe en algunos casos emitir sentencias "moduladas", es decir, sentencias que reglamenten los efectos ya sea en el tiempo, en el modo o en

38 SAGÜES, Néstor Pedro. Compendio de derecho procesal constitucional. Buenos Aires: Astrea, 2009. p.29. 
lugar donde se aplican. Las dos tesis planteadas no son necesariamente contrapuestas, ya que perfectamente la Corte según el caso en concreto puede tomar una u otra postura.

No obstante, es menester hacer un estudio acerca de cuál es la postura correcta que debe asumir como tribunal internacional. Lo anterior encaminado a establecer si las actuaciones en ejercicio de funciones jurisdiccionales de los Tribunales Constitucionales internos se someten al Control de Convencionalidad de la Corte Interamericana.

\subsection{Casos}

Para tratar de buscar una solución argumentada acerca de problemática planteada, se va hacer cita y análisis de casos hitos, es decir, casos donde la Corte Interamericana ha sentado criterios novedosos sobre la temática.

\subsubsection{Caso Apitz Barbera y otros vs. Venezuela}

La demanda se relaciona con la destitución de los exjueces de la Corte Primera de lo Contencioso Administrativo Ana María Ruggeri Cova, Perkins Rocha Contreras y Juan Carlos Apitz Barbera el 30 de octubre de 2003, por haber incurrido en un error judicial inexcusable al conceder un amparo cautelar que suspendió los efectos de un acto administrativo que había negado el registro de una compraventa.

Al ser notificados de esta decisión, los magistrados Apitz y Rocha interpusieron, en contra de la sanción de destitución, un recurso jerárquico (derecho de amparo) ante la Sala Plena del Tribunal Supremo de Justicia alegando la incompetencia de la CFRSJ para destituirlos, recurso que fue desechado.

La Corte Interamericana al sentenciar este caso consideró:

"El Estado no garantizó el derecho de los señores Juan Carlos Apitz Barbera y Perkins Rocha Contreras y de la señora Ana María Ruggeri Cova a ser juzgados por un tribunal imparcial, lo que constituye una violación del artículo 8.1 de la Convención Americana sobre Derechos Humanos, en relación con las obligaciones generales consagradas en los artículos 1.1 y 2 de la misma (...) y "El Estado violó el derecho a un recurso sencillo, rápido y efectivo, consagrado en el artículo 25.1 de la Convención Americana sobre Derechos Humanos, en relación con el artículo 1.1 de la misma, en perjuicio de los señores Juan Carlos Apitz Barbera y Perkins Rocha Contreras, conforme a los párrafos 150 a 156 y 171 de esta Sentencia".

Por las anteriores consideraciones y algunas otras, la Corte IDH condeno al Estado a:

"El Estado debe reintegrar al Poder Judicial a los señores Juan Carlos Apitz Barbera y Perkins Rocha Contreras y a la señora Ana María Ruggeri Cova, si éstos así lo desean, en un cargo que tenga las remuneraciones, beneficios socia- 
les y rango equiparables a los que les correspondería el día hoy si no hubieran sido destituidos. Si por motivos fundados, ajenos a la voluntad de las víctimas, el Estado no pudiese reincorporarlas al Poder Judicial en el plazo de seis meses a partir de la notificación de la presente Sentencia, deberá pagar a cada una de las víctimas la cantidad establecida en el párrafo 246 de esta Sentencia”.

De la anterior sanción citada textualmente de la sentencia de la Corte Interamericana se extrae que implícitamente anula los efectos de todas las providencias emitidas por los juzgadores internos del Estado venezolano, incluyendo obviamente la decisión de Tribunal Supremo de Justicia al decidir el amparo.

El derecho de amparo venezolano es un recurso que se puede equiparar, guardada las proporciones, con la petición de tutela en Colombia, habida cuenta que ambos son mecanismos establecidos con el objeto de garantizar la efectividad, el respeto y la garantía de derechos fundamentales.

\subsubsection{Caso La última tentación de Cristo vs. Chile}

En este caso, la Corte Interamericana, además de declarar la responsabilidad internacional del Estado chileno, le ordenó modificar el art. 19 de su Constitución Política, a efectos de asegurar el cumplimiento del derecho a la libertad de expresión.

\subsubsection{Caso Suárez Rosero contra Ecuador}

La Corte Interamericana declaró que una norma del Código Penal de Ecuador era violatoria per se del art. 2 de la Convención lo que implicaba el retiro del ordenamiento.

\subsubsection{Caso Castillo Petruzzi y otro vs. Perú}

La Corte Interamericana le ordenó a Perú que modificara las normas que permitían el juzgamiento de civiles por militares, a través de la justicia "sin rostro", por ser contrarias a la Convención.

\subsubsection{Caso Castañeda Gutman vs. Estados Unidos Mexicanos}

La Corte Interamericana dispuso en contra de México, que en un plazo razonable debía "completar la adecuación de su derecho interno a la Convención, de tal forma que ajuste la legislación secundaria y las normas que reglamentan el juicio de protección de los derechos del ciudadano".

\subsubsection{Caso Roxcacó Reyes vs. Guatemala}

La Corte Interamericana ordenó a Guatemala, en concreto a la Corte Suprema de ese país, dejar sin efecto la pena impuesta a un ciudadano, señalando que debía emitir otra que en ningún caso podrá ser la pena de muerte. 


\subsection{Un caso especial: caso Artavia Murillo y otros vs. Costa Rica}

En Costa Rica, a partir de $1995^{39}$, se permitió la utilización de técnicas asistidas para el nacimiento de seres humanos, específicamente se autorizaba la práctica de la fecundación in vitro (FIV $)^{40}$. El mismo año de expedición de la norma que regulaba las técnicas de reproducción asistida in vitro, fue demandada por un ciudadano de este país, pretendiendo que se declarara la inconstitucionalidad, argumentando violaciones al derecho a la vida. La Corte Suprema de Justicia, Sala Constitucional, emitió sentencia en el año $2000^{41}$ declarando nula la norma mencionada por ser contraria a la Constitución del Estado de Costa Rica. Los argumentos que esgrimió la Sala Constitucional fueron básicamente dos: uno de carácter orgánico y el otro de carácter sustancial; el primero consiste en la violación por parte del ejecutivo de regular asuntos que son de competencia de manera exclusiva de la rama legislativa; el segundo se centra en la supuesta violación al derecho fundamental a la vida; la Sala le otorgó prevalencia a este último motivo:

“(...) por lo que la técnica no es acorde con el Derecho de la Constitución y por ello el reglamento cuestionado es inconstitucional por infracción al artículo 21 de la Constitución Política y 4 de la Convención Americana sobre Derechos Humanos. Por contravenir la técnica, considerada en sí misma, el derecho a la vida, debe dejarse expresa constancia de que, ni siquiera por norma de rango legal es posible autorizar legítimamente su aplicación, al menos, se insiste, mientras su desarrollo científico permanezca en el actual estado y signifique el daño consciente de vidas humanas" ${ }^{\prime \prime 2}$.

El 30 de mayo de 2008, una ciudadana costarricense interpuso una demanda pretendiendo que se declarara la inconstitucionalidad de la sentencia proferida por la Sala Constitucional, a lo que el alto tribunal respondió afirmando que tal actuación no era procedente, por lo que rechazó de plano la demanda.

La declaración de inconstitucionalidad de las normas que permitían el procedimiento de fecundación in vitro, llevó a que a muchas parejas se les negara la posibilidad de practicarse tal procedimiento, siendo el caso más representativo el de Grettel Artavia Murillo y Miguel Mejías Carballo ${ }^{43}$.

39 Costa Rica. Ministerio de Salud. Decreto Ejecutivo No. 24029-S (3 de febrero de 1995).

40 "Es la unión del óvulo de una mujer y el espermatozoide de un hombre en un plato de laboratorio. In vitro significa "por fuera del cuerpo". Fecundación significa que el espermatozoide se ha fijado y ha ingresado al óvulo”. Definición tomada de la página Web http://www.nlm.nih.gov/ medlineplus/spanish/ency/article/007279.htm

41 Sentencia No. 2000-02306 de 15 de marzo de 2000 de la Sala Constitucional de la Corte Suprema de Justicia, exp. 95-001734-007-CO.

$42 \quad$ Ibídem, f. 94 y 95.

43 "La señora Grettel Artavia Murillo contrajo matrimonio con el señor Miguel Mejías Carballo el 13 de diciembre de 1993. A raíz de un accidente laboral ocurrido en 1985, el señor Mejías 
La Comisión Interamericana de Derechos Humanos, sometió en 2011 el caso ante la jurisdicción de la Corte Interamericana de Derechos Humanos. La Comisión indicó que la decisión de la Sala Constitucional generaba, entre otros aspectos: (i) una injerencia arbitraria en los derechos a la vida privada y familiar, (ii) una violación al derecho de igual de las víctimas, por lo que solicitó que se declarara la responsabilidad internacional del Estado por la violación de los arts. 11.2, 17.2 y 24 de la Convención Americana.

En este caso el sujeto que produjo la violación de los derechos convencionales es la Corte Suprema de Justicia de Costa Rica, concretamente la Sala Constitucional, la cual dictó una providencia que debido a la decisión de declarar inconstitucional una norma del inferior jerarquía, ocasionó la violación de derechos de un grupo de personas: estamos ante una pugna entre la interpretación de la Constitución que hace el máximo órgano de la jurisdicción constitucional y la interpretación de la Convención Americana que hace la Corte Interamericana de Derechos Humanos, o lo que es lo mismo, un control de constitucionalidad contra un control de convencionalidad.

La Corte Interamericana dictó la sentencia para resolver la pretensión alegada por la Comisión en defensa de los derechos de las parejas costarricenses el 28 de noviembre de 2012, en la que resolvió que el Estado de Costa Rica, producto de la sentencia de la Sala Constitucional de la Corte Suprema de Justicia, violó los arts. 5.1, 7, 11.2, 17,2, en relación con el art. 1.1 de la Convención Americana. En palabras del tribunal internacional: "Por tanto, la Corte concluye que la Sala Constitucional partió de una protección absoluta del embrión que, al no ponderar ni tener en cuenta los otros derechos en conflicto, implicó una arbitraria y excesiva intervención en la vida privada y familiar que hizo desproporcionada la interferencia. Asimismo, la interferencia tuvo efectos discriminatorios" ${ }^{\prime 4}$.

Los tribunales que tienen la importante tarea de proteger la integridad y supremacía de la Constitución no escapan a la falibilidad de los seres humanos, por

sufrió un accidente a la edad de 19 años que lo dejó parapléjico permanentemente, razón por la cual decidieron buscar ayuda médica. La médica tratante diagnosticó la imposibilidad de la pareja para procrear naturalmente, por lo que era imposible llegar a un embarazo sin asistencia médica. Teniendo en cuenta lo anterior, les realizó ocho inseminaciones artificiales. Para sufragar los gastos de las inseminaciones, la pareja solicitó créditos fiduciarios e hipotecarios e hipotecó su casa, además de vender algunas de sus pertenencias. Sin embargo, las inseminaciones artificiales no dieron resultado. En febrero de 2000, la médica tratante le informó a la pareja que la última alternativa a seguir en el tratamiento contra la infertilidad sería practicar una FIV. Un mes después, el 15 de marzo de 2000 la Sala Constitucional de Costa Rica emitió la sentencia que prohibió la práctica en el país. La pareja no tenía los recursos económicos para viajar al exterior para realizarse el tratamiento. El 10 de marzo de 2011 la pareja se divorció, siendo una de las razones la imposibilidad de tener hijos biológicos".

44 Corte Interamericana de Derechos Humanos. Caso Artavia Murillo y otros ("fecundación in vitro") vs. Costa Rica. Sentencia del 28 de noviembre de 2012. p. 99, Consideración 316. 
lo que los ordenamientos jurídicos deben brindar mecanismos de protección para cuando sea el máximo tribunal de la jurisdicción constitucional de un Estado el que ocasione la vulneración a un derecho: garantías que controlen el poder. Este caso demuestra que la Corte Interamericana en un mecanismo para controlar las actuaciones de los Estados, incluyendo las de sus tribunales constitucionales.

\section{CONClusiones}

1. La Corte Constitucional, como cualquier juez, puede violar derechos fundamentales. En consecuencia, las providencias que lo hagan no pueden hacer tránsito a cosa juzgada, es decir, la Cosa Juzgada Constitucional que establece el art. 243 de la Constitución Política no es absoluta ${ }^{45}$.

2. Existen tres mecanismos excepcionales, residuales y subsidiarios para defendernos cuando una sentencia de la Corte viole un derecho fundamental: la solicitud de nulidad, la petición de tutela y el Sistema Interamericano de Derechos Humanos.

3. Las actuaciones de la Corte Constitucional colombiana se pueden someter al Control Convencional que la Corte Interamericana haga si se le pone de conocimiento el caso.

\section{REFERENCIAS}

ALEXY, Robert. El Concepto y la Validez del Derecho. Barcelona: Gedisa, 1994. Teoría de la Argumentación Jurídica. Madrid: Centro de Estudios Constitucionales, 1989.

Colombia. Corte Constitucional. Auto 93 de 2002, MP Marco Monroy Cabra. Conflicto de competencia ICC-322.

BERIZONCE, Roberto Omar. "La 'Relatividad' de la Cosa Juzgada y sus Nuevos Confines". En: Revista del Instituto Colombiano de Derecho Procesal. Edición 38. Bogotá, D.C.: Ediciones del profesional LTDA., 2012.

45 "Lo último pero no menos importante: no hay noción, concepto y fundamento político que se escriba de una vez y para siempre. La cosa juzgada, concepto típicamente político está inevitablemente condenada a transfigurarse y mutar a partir de su consustancial "relatividad". Cuál sea el grado de esa relatividad, los desplazamientos hacia uno y otro extremo de la balanza, que expresan más o menos seguridad jurídica vs. más o menos justicia, depende inexorablemente de los principios y valoraciones que en cada época y en cada circunstancia van prevaleciendo. El desafío de los juristas - doctrinarios, jueces y abogados-radica en ajustar y calibrar lo más exactamente posible el fiel de esa tan sensible balanza. Para colocarla en un punto medio razonable que, en los tiempos que transcurren, sin escozor de la esencia del principio de anida en la salvaguarda de la seguridad jurídica, permita el paso a las ansias de justicia que trasuntan en el difuso y difícilmente aprehensible inconsciente colectivo, tanto como en el concreto reclamo de los justiciables. Nada más, pero tampoco, nada menos". BERIZONCE, Op. cit. p. 107. 
DÍAZ AYA, Mónica Yineth. "Análisis Jurisprudencial: pronunciamiento del Consejo de Estado sobre la Tutela contra Tutela". En: Revista Derecho del Estado, Universidad Externado de Colombia. 2008, núm. 21.

FERRAJOLI, Luigi. El Garantismo y la Filosofía del Derecho. Bogotá DC: Universidad Externado de Colombia, 2000.

KELSEN, Hans. ¿Quién Debe ser el Defensor de la Constitución? Madrid: Tecnos SA. 1995.

. Teoría General del Derecho y del Estado. México. 1950.

. Teoría Pura del Derecho. México: Universidad Nacional Autónoma de México. 1982.

LLAMBÍAS, Jorge Joaquín. Efectos de la Nulidad y de la Anulación de los Actos Jurídicos. Buenos Aires: Edic. Arayú. 1953.

LÓPEZ MEDINA, Diego Eduardo. El Derecho de los Jueces. Segunda edición. Bogotá: LEGIS, 2011.

SAGÜES, Néstor Pedro. Compendio de Derecho Procesal Constitucional. Buenos Aires: Astrea, 2009.

QUINCHE RAMíREZ, Manuel Fernando. Vías de Hecho Acción de Tutela contra Providencias. $5^{\text {a }}$ ed., Bogotá.

. "El Control de Convencionalidad y el Sistema Colombiano". En: Revista Iberoamericana de Derecho Procesal, núm. 12, Julio-Diciembre de 2009. 